\title{
APPLICATION OF ANP IN THE CATCH-UP STRATEGY FORMULATION OF INDONESIAN TELECOMMUNICATION INDUSTRY
}

\author{
Didit Herawan* \\ Department of Industrial Engineering \\ Bakrie University \\ Jakarta, Indonesia \\ Email: didit.herawan@bakrie.ac.id
}

\begin{abstract}
In the current rapid growing telecommunication sector, Indonesian Telecommunication industry has to redefine its strategy in catching-up and leapfrogging the market leader countries. This paper describes the use of Analityc Network Process (ANP) in building a strategy selection model of Indonesian Telecommunication Industry. The model construction integrates three main theories, namely: industry catch-up strategy framework, Sectoral Innovation System and Analytic Network Process. The modeling process applied ANP as the basic framework of multi criteria decision making, using 5 alternative strategies and 27 elements of selection criteria clustered in seven components. The model employs a questionnaire of 1302 pairwise comparisons, which were judged by five experts of the industry. The result suggests that pioneering application strategy is considered as the most appropriate strategy for the industry to catch up, while the other strategies could be considered as the next step strategies in the scenario. Influences and feedbacks of each element in the innovation system were studied through the supermatrix result but only partially reported in this paper.
\end{abstract}

Keywords: Industry Catch-Up Strategy, Sectoral Innovation System, Analytic NetworkProcess, Indonesian Telecommunication Industry.

\section{Introduction}

The development of telecommunications sector is heavily influenced by its fast technological change. Indonesia, with a total population of 240 million, records a number of 200 million telephone subscribers by April 2011. Only five percent use fixed line or home telephone, while the rest utilize mobile phone services. The industry growth has been dominated by the service sector, particularly communication services and very little contributions from the production or manufacturing sector. The government's efforts to push manufacturing sector has not been successful. The fact, more than half of telecommunication manufacturing companies, which started in the 70s and $80 \mathrm{~s}$, have changed their business focus to services. Some researchers indicate that both sectoral and national innovation systems Indonesia has not been properly developed with a clear strategy. There is no firm direction from the Government in the development of the industry, particularly in the manufacturing sector. At least there should be a balance in the development among product, process, or technology application approach. The big question is what strategy should be set in order to lead the current innovation system for Indonesia telecommunication industry?

To answer to the above-MENTIONED question, the author conducted a research of strategic management and innovation system approaches. Strategic management approach helps in formulating strategy, while innovation system approach helps in identifying key innovation factors. Both approaches require an integrator to link them, which is best served by Analityc Network Process (ANP) methodology. In this research, the strategy formulation is implemented at the sector or industry level as a dominant path of the industry.

\footnotetext{
* Corresponding author
} 


\section{Integration of Theories in the Model Development}

There are three essential theories in developing the model as a strategy formulation tool. The first theory is the catch-up strategy framework of industry development (Wong, 1999). This theory was developed from a study on the differences of industry development path of Korea, Singapore and Taiwan in early 1980s. The study led to five alternativestrategies, i.e.: Reverse Value Chain strategy, Reverse Product Life Cycle Innovation strategy, Process Capability Specialist strategy, Product Technology Pioneering strategy and Application Pioneering strategy. The deescrition can be seen in Tabel 1. There are many other studies on industrial innovation or development, such as:on the rise of technology at the micro level, macro and public policy (Freeman and Soete, 1997), and three stages of industry development of original equipment manufacturer (OEM), own design and manufacture (ODM) and own brand manufacturing (OBM) (Hobday, 2000). Benchmarking among those studies showed that Wong's approach was the most complete view in capturing all development stages.

Table 1. Dominant Path Strategy Alternative of Industry Catch-up (Wong, 1999)

$\begin{array}{ll}\text { Reverse Value Chain Strategy: } & \begin{array}{l}\text { The latecomer firms learn the technology by mastering } \\ \text { assembly or product sub-component manufacturing. }\end{array} \\ & \text { The latecomer firms acquire the technology by learning to } \\ \text { peverse Product Life Cycle } & \text { usually targeted at the low-price market segments. } \\ \text { Innovation Strategy: } & \text { The latecomer firms concentrate on their manufacturing } \\ & \text { capabilities by mastering the latest process technologies that } \\ \text { Process Capability Specialist } & \text { yield the best performance as demanded by the market, } \\ \text { Strategy: } & \text { whether the lowest cost, highest quality, maximal flexibility, } \\ & \text { or some combination. } \\ & \text { The latecomer firms seek to leapfrog others through radical } \\ & \text { product technology innovations. It is the most difficult } \\ \text { strategy for latecomer firms from late industrializing } & \text { countries. } \\ \text { Product Technology Pioneering } & \text { The latecomer firms focus their efforts in the application of } \\ & \text { existing technologies in new innovative ways, typically in a } \\ & \text { business area where the organization has considerable } \\ \text { complementary skills. }\end{array}$

The second theory is the Sectoral Innovation System which is a suitable approach to understand the dynamic of the sector or industry. This framework is characterized by the role of three major components, namely: actors, know ledge and technology, and institutions (Malerba, 2004). An indepth study on innovation system byLeydesdorff and Etzkowitz (1995) showed the importance of three groups of actors: Industry, Government, and University. Their role and contributions determine the success of the innovation system. The component of knowledge and technology represents the required and generated component during the interactive learning in the innovation system. This component is then translated into the three elements of importance concerning the readiness of the system, Traffic acquisition system and the risks posed by technological change (Lundvall, 1992; Malerba, 2004). The institutional component, which includes formal and non-formal rules in the innovation system is separated into three components, namely: Industry network (Ahuja, 2000), Market Conditions and Business Culture (Engardio, 2007), and Industrial Policy (Taufik, 2006). Each of these components can be explained by the elements that influence it. Networking Components Industry is translated into the elements: funding, research and development, supply chain, marketing, and telecommunications and transportation. Components of Market Conditions and Business Culture are set out in the elements: the availability of markets, collaboration, competition, political influence, and the patent process. While the Industrial Policy components are translated into the elements: policy research and development, fiscal and tax policy, industrial policy, education policy, telecommunications regulation. All these elements are obtained based on the theory exploration of 
sectoral innovation system of Indonesian telecommunications industry. The existence and role of these elements affect and determine strategies for developing the innovation system (catch-up strategy).

The third theory is the Analytic Network Process (ANP) as a multi criteria decision making method. According to Saaty (1999), "ANP is a general theory of relative measurement used to derive compos ite priority ratio scales from individual ratio scales that represent relative measurements of the influence of elements that interact with respect to control criteria. Through its supermatrix whose elements are themselves matrices of column priorities, the ANP captures the outcome of dependence and feedback within and between clusters of elements. The Analytic Hierarchy Process (AHP) with its dependence assumptions on clusters and elements is a special case of the ANP. The ANP is a new and an essential phase in decision making, and is neglected so far because of the linear structures used in traditional approaches and their inability to deal with feedback in order to choose alternatives not simply according to attributes and criteria, but also according to the ir consequences both pos itive and negative". The structure of ANP provides an opportunity to integrate the other two theories to solve the issue.

\section{ANP Model Construction}

The ANP model construction was completed through several steps: (a) development of a theoretical model, (b) review of the theoretical model by a focus group discussion (FGD) of five industry experts, (c) implementing the model on SuperDecissions ${ }^{\circledR}$ software tool, (d) testing the model and questionnaire on limited respondents and improving them based on the test results, (e) conducting FGD with five selected industry experts which was followed by expert judgement on the questionnaire (quantification of the questionnaire), and (f) analyzing the result.

The role of experts' selection and involvement is critically important to the development of the model. Experts' in depth understanding as well as their neutral view on the industry are required to support the process. This study involved two groups of experts, five experts each at step (b) and step (e). The first expert group were involved in confirming the research model and the second expert group members were asked to judge on the pairwise questionaire.

In the focus group discuss ion and model review with the experts, two additional components were added to the model. The first one is Actor Characteristics with its elements: leadership, entrepreneurship, creativity, and the second additional component is Time Frame, with its elements: short term, medium term, and long term. Figure 1 shows the complete ANP model of catch-up strategy selection.

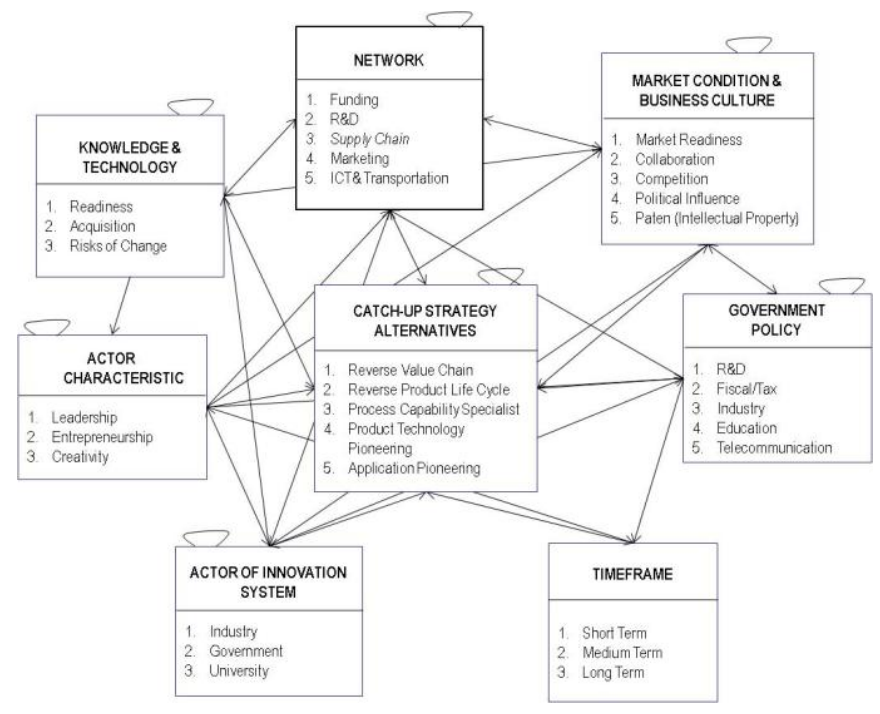


Figure 1. ANP Model of Catch-Up Strategy Selection.

The model was implemented into the supporting tool software SuperDecisions®. It produced a questionnaire of 1302 pairwise comparisons, which was distributed to the experts in a more userfriendly questionaire hardcopy format. Synthesis of the model is not only strategy selection, but also influence of each element of the innovation system.

\section{Result Analysis}

Model quantification using SuperDecisions ${ }^{\circledR}$ produced: unweigthed supermatrix, weigthed supermatrix and limiting supermatrix. The limiting supermatrix is shown in Table 2. The result represents the combined expert judgement on the importance of each element (influence and feedback) within the alternative cluster and criteria clusters.

On the cluster of alternatives, the highest score is given to application pioneering strategy followed by reverse product life cycle innovation strategy, reverse value chain strategy, process capability specialist strategy, and product pioneering technology strategy. Application pioneering strategy is considered the most appropriate strategy for the current development of Indonesian telecommunications industry. The innovation capability of the firms in the industry is better to be prepared toward implementing new technology's product or services rather than producing a competing new technology to the existing one.

Table 2. Result of Limiting Matrix in Each Cluster

\begin{tabular}{|c|c|c|c|}
\hline \multicolumn{2}{|l|}{ CLUSTER/COMPONENT: ALTERNATIVES } & & \\
\hline \multicolumn{2}{|l|}{ Catch Up Strategy } & & \\
\hline Application Pioneering & 0.061 & & \\
\hline Reverse Product Life Cycle Innovation & 0.053 & & \\
\hline Reverse Value Chain & 0.052 & & \\
\hline Process Capability Specialist & 0.043 & & \\
\hline Product Technology Pioneering & 0.032 & & \\
\hline \multicolumn{4}{|c|}{ CLUSTER/COMPONENT: SELECTION CRITERIA (SECTORAL INNOVATION SYSTEM) } \\
\hline \multicolumn{2}{|l|}{ Actors of Innovation System } & \multicolumn{2}{|l|}{ Knowledge \& Technology } \\
\hline Industry & 0.062 & Acquisition & 0.054 \\
\hline Iuniversity & 0.031 & Readiness & 0.047 \\
\hline Government & 0.026 & Risk of Change & 0.036 \\
\hline \multicolumn{2}{|l|}{ Characteristic of Actors } & \multicolumn{2}{|c|}{ Market Condition \& Business Culture } \\
\hline Entrepreneurship & 0.011 & Market Availability & 0.051 \\
\hline Creativity & 0.010 & Collaboration & 0.042 \\
\hline \multirow[t]{2}{*}{ Leadership } & 0.007 & Competition & 0.037 \\
\hline & & Patent (Intelectual Property) & 0.022 \\
\hline \multicolumn{2}{|l|}{ Business Networks } & Political Influence & 0.017 \\
\hline Funding & 0.043 & & \\
\hline Marketing & 0.036 & Government Policy & \\
\hline Supply Chain & 0.028 & Industry & 0.029 \\
\hline Research \& Development & 0.028 & Research \& Development & 0.024 \\
\hline \multirow[t]{2}{*}{ ICT \& Transportation } & 0.019 & Fiscal \& Tax & 0.022 \\
\hline & & Telecom Regulation & 0.020 \\
\hline Time Frame & & Education & 0.017 \\
\hline Short Term & 0.022 & & \\
\hline Medium Term & 0.011 & & \\
\hline Long Term & 0.007 & & \\
\hline
\end{tabular}

As further discussed with the experts, the other respective strategies may indicate the direction of further development in the industry. Technology application stage is users' familiarization of the technology before the industry is able to move to the next step of implementing a reverse engineering 
process (through value chain or product life cycle innovation). The following step is to master the process, before able to design and further to manufacture the products.

Table 2 also shows the influence of prioritizing components and elements of criteria. Those which have relatively high score are: the Industry as an actor, the ability to acquire new knowledge \& technology, market availability, the readiness of knowledge and technology, funding availability, and collaboration. The actor of Industry has a major role in the successful implementation of application pioneering. Meanwhile, in the same cluster, Government and University are shown to have less significant role. In fact, in current industry situation, the role of government and universities are immaterial in industrial innovation. This does not support the ideal conditions growth driver of innovation systems, where there is a balance of roles between these three actors (Leydesdorff and Etzkowitz, 1995). The next higher rating is given to the capabilities and readiness of the acquisition of knowledge and technology. This strengthens the indication that local firms generally do not have sufficient capability to create innovation through the acquisition of knowledge. In most collaboration of local companies with foreign technology owner companies, the local company works more as facilitator of relationships with customers or as a trader. The local companies are not capable to acquire the technical know ledge and expertise from their partner.

Another element that is also of importance role is the availability of market, funding network, and collaboration. Availability of provided market is required to ensure constant demand of local products, thus giving an opportunity for domestic companies to prepare costs for research and improvement of its products ("infancy period"). Funding needs to be easy for entrepreneurs, especially in the early stages of their business. The model alsos shows all influences and feedbacks among related elements, but they are not discussed in this paper.

\section{Conclusions}

The study has shown that the ANP model fits suitably as a new analytical tool of strategic management and system innovation to prioritize and choose the best strategy for Indonesian telecommunications industry. It quantitatively measured the decision process in selecting strategy using certain criteria. In this study, the ANP integrates the strategic framework as alternatives, with sectoral innovation system's elements as selecting criteria. The role of experts is crucial at any stage of the model construction from model quantification to result analysis. The more complex the model, the more structured explaination can be drawn. It may not change the selection result, but it provides a better reasoning in the decision making which includes dependences and feedbacks among elements.

The result of the model quantification indicates that application pioneering strategy is the suitable strategy for Indonesian Telecommunication Industry. Although Indonesia has developed its manufacturing capability few decades ago, rapid change in technology and current condition of the country have put the industry back to the beginning of technology learning curve, in which application of technology is the most appropriate path to take. The understanding of current sectoral innovation system, focusing in the improvement of actors' roles, knowledge readiness and acquisition, market availability, and collaboration or partnership will speed up technology catch-up more effectively and efficiently. This audit-like process to the innovation system and strategy should be implemented regularly and continuously. It is to ensure progress in the industry and increases nation's competitiveness.

\section{Implications and Recommendations for Future Research}

An important theoretical implication of this research is the creation of new analytical tools in Strategic Management at the stage of environmental analysis and strategy formulation. The deployment of this research model also provides enrichment on: strategy framework of technological innovation from 
Wong (1999), system innovation sector of Malerba $(1999,2004)$, and application of ANP in the category of business strategy (Saaty\&Özdemir, 2005; Saaty\&Cillo, 2008).

As a continuation to this study, future researches are recommended, such as: a broader scope research which covers several industries at a national level and a many researches at the company level as part of the micro economic sector. Both can be done us ing a combination of AHP and ANP with benefits, opportunity, cost and risk (BOCR) concept. Modeling with such high complexity can be done to better understand industry problems (Saaty, 2005).

\section{REFERENCES}

Ahuja, G. (2000). Collaboration Networks, Structural Holes, and Innovation: A longitudinal St udy. Administrative Science Quarterly. Vol. 45, No. 3, pg. 425.

Engardio, P. (Ed.). (2007). CHINDIA: How China and India are Revolutionizing Global Business. McGraw Hill

Leydesdorff, L., \& Etzkowitz, H. (1995). The Triple Helix: University-Industry-Government Relations: A Laboratory for Knowledge Based Economic Development. European Society for the Study of Science and Technology. Vol. 14 (1), March 1995.

Lundvall, B.-A. (Ed.) (1992). National Systems of Innovation: Towards a Theory of Innovation and Interactive Learning. London: Pinter.

Lundvall, B.-A (2004). National Innovation Systems - Analytical Concept and Development Tool. Dynamics of Industri and Innovation: Organizations, Networks and Systems. Copenhagen, Denmark.

Malerba, F. (1999). Sectoral Systems of Innovation and Production. DRUID Conference on: National Innovation Systems, Industrial Dynamics and Innovation Policy. Rebild, June 9-12, 1999.

Malerba, F. (2004). Sectoral Systems of Innovation: Concepts, Issues and Analysis of Six Major Sector in Europe. Cambridge University Press, Cambridge, UK.

Saaty, T.L. (1999). Fundamentals of the Analytic Network Process. ISAHP 1999, Kobe, Japan, August 12-14, 1999.

Saaty, T.L. (2005). Theory and Applications of the Analytic Network Process: Decision Making with Benefits, Opportunities, Costs, and Risks. RWS Publication, Pittsburgh.

Saaty, T.L. (2010). Principia MathematicaDecernendi: Mathematical Principles of Decision Making . RWS Publications, Pittsburgh.

Taufik, T.A. (2005). Pengembangan Sistem Inovasi Daerah: Perpektif Kebijakan. Pusat Pengkajian Kebijakan Teknologi Pengembangan Unggulan Daerah dan Peningkatan Kapasitas Masyarakat, BPPT \& RISTEK, Jakarta.

Wong, P.K. (1999). National Innovation Systems for Rapid Technological Catch-Up: An analytical framework and a comparative analysis of Korea, Taiwan and Singapore. DRUID Summer Conference on National Innovation Systems, Industrial Dynamics and Innovation Policy. Rebild, Denmark. 